\title{
LAS AMBICIONES DE LA NEUROÉTICA: FUNDAR CIENTÍFICAMENTE LA MORAL
}

\section{Gustavo Figueroa $^{1}$}

Resumen: Los progresos recientes en neurociencias han desembocado en problemas éticos. La neurociencia de la ética investiga los mecanismos neurales que posiblemente subyacen a los conceptos y prácticas éticas. El método científico moderno excluye de entrada todos los objetos posibles de investigación científica que no puedan ser reducidos a fenómenos sensoriales observables y mensurables. Pero la esencia del hombre no es ser-ante-los-ojos, sino "existencia". Contrariamente a todas las otras criaturas, el ser humano se caracteriza por ser comprensor del ser. Como ser-en-el-mundo el hombre está perdido en su cotidianidad en una disipación óntica. Él escucha a su voz de la consciencia cuando lo llama a la autenticidad, es decir, hacia su potencialidad más propia y a aceptar su finitud constitutiva.

Palabras clave: neuroética, neurobiología de la ética, voz de la conciencia, autenticidad, objetivación

\section{The ambitions of neuroethics: to find the scientific fundament of morals}

Abstract: The recent progress in neuroscience has led to ethical questions. The neuroscience of ethics investigates the neural mechanisms that may possibly underlie ethical concepts and practices. The modern scientific method rules out in advance as possible objects of scientific investigation all phenomena that cannot be reduced to observable and measurable sensory phenomena. But the essence of man is not "entity" as such (present) but "existence". Like no other creature awareness of being characterizes him most profoundly. As being-in-the-World humans are lost in their everyday life in ontic dissipation. He listens to the voice of conscience when this call to authenticity, that is, unto its own proper potentiality, and unto accepting his constitutive finitude.

Key words: neuroethics, neurobiology of ethics, voice of conscience, authenticity, targeting

\section{As ambiçóes da neuroética: fundar cientificamente a moral}

Resumo: Os progressos recentes em neurociências têm desembocado em problemas éticos. A neurociência da ética investiga os mecanismos neurais possivelmente subjacentes nos conceitos e práticas éticas. O método científico moderno exclui de entrada todos os objetos possíveis de investigação científica que não podem ser reduzidos a fenômenos sensoriais observáveis e mensuráveis. Porém, a essência do homem não é ser-diante-dos-olhos, senão "existir". Contrariamente a todas as outras criaturas, o ser humano se caracteriza por aquele que compreende o ser. Como ser-no-mundo o homem está perdido em sua cotidianidade numa dissipação ôntica. Ele escuta a voz da consciência quando o chama à autenticidade, ou seja, para a sua potencialidade mais própria e a aceitar a sua finitude constitutiva.

Palavras-chave: neuroética, neurobiologia da ética, voz da consciência, autenticidade, objetividade

\footnotetext{
${ }^{1}$ Departamento de Psiquiatría, Escuela de Medicina, Universidad de Valparaíso, Chile Correspondencia: gfigueroacave@gmail.com
} 
El neurocientífico y ganador del Premio Nobel, Francis Crick, afirmó hace menos de una década: "Usted, sus alegrías y sus penas, sus recuerdos y sus ambiciones, su sentido de la identidad personal y su libre albedrío no son de hecho más que la conducta de una vasta asamblea de células nerviosas y de las moléculas a ellas asociadas" (1). Ocho años después, una comisión proclamó públicamente, en un nutrido congreso en San Francisco, el nacimiento de la neuroética y la definió como "el estudio de las cuestiones éticas, legales y sociales que surgen cuando los descubrimientos científicos acerca del cerebro se llevan a la práctica médica, las interpretaciones legales y las políticas sanitarias y sociales" (2).

Estas aseveraciones pronunciadas al despuntar el siglo XXI tienen un sustento común: en los últimos decenios las neurociencias han alcanzado un progreso hasta hace poco no imaginado, superando las expectativas más auspiciosas y, por momentos, llevando a la realidad fantasías elaboradas en relatos de anticipación dura(3). Pero lo más interesante proviene de otro lado: los datos y conocimientos empíricos sobre el funcionamiento de determinadas zonas o circuitos del cerebro han trascendido los estrictos márgenes médicos y están dando definiciones sobre qué es lo propiamente humano de nuestra condición. Así, por una parte, las osadas opiniones de Crick son un ejemplo que da por evidente una concepción del hombre, no se pregunta por sus fundamentos, da por supuesta su esencia y los experimentos escogidos y ejecutados promueven y confirman esta noción. Simultáneamente, numerosos investigadores han procedido de igual manera y también han entregado dictámenes sobre la naturaleza del hombre sustentándose en sus propios ensayos, y lo han caracterizado como "cerebro que piensa", "mente computacional", "hombre neuronal", "cerebro empático", "cerebro ético", "self sináptico" sin "zombies filosóficos" (4-10).

Por otro lado, los sorprendentes alcances éticos de estos estudios neurobiológicos hicieron nacer la neuroética para reconocer lo correcto o incorrecto, bueno o malo, en el tratamiento, perfeccionamiento, intromisiones o manipulaciones del cerebro humano(11). Roskies diferenció al interior de la neuroética la ética de las neurociencias de la neurociencia de la ética(12). La ética de las neurociencias trata con los problemas éticos que surgen de las intervenciones y nuevas tecnologías que actúan sobre el cerebro (estimulantes neuronales, supresión de recuerdos traumáticos, detección de mentiras por medio de neuroimágenes, predicción de enfermedades, neuroprótesis, etc.). La neurociencia de la ética investiga los mecanismos neurales que supuestamente subyacen a condiciones éticas, como el juicio moral, el libre albedrío, la voluntad, la autonomía, la responsabilidad. Esto significa distinguir dentro de la neuroética dos ramas diferentes: una neuroética aplicada, que pertenecería propiamente a la bioética médica, y una neuroética fundamental, que propondría las bases neuroquímicas y cerebrales de la ética misma(13).

Nos interesa la neuroética fundamental porque, producto de las neurociencias, tiene metas de alcance revolucionario. Aspira a producir un giro radical en la ética en un triple sentido: entregar una visión científica de la génesis de la moralidad en el hombre, dar las bases para eleborar una ética universal común, fundada en las ciencias positivas, y, a partir de hallazgos empíricos, replantearse cuestiones morales primordiales como libre albedrío, determinismo, autonomía, buena voluntad. En otras palabras, ambiciona no sólo dar una perspectiva innovadora a la bioética tal como la conocemos desde su gestación en los años 70, sino asumir y superar la ética occidental tradicional procedente de Grecia, proporcionándole un nuevo fundamento inédito hasta ahora.

La finalidad del presente trabajo es doble. Primero, dar una visión sinóptica de los estudios neurobiológicos y de las teorías centrales de la neuroética fundamental, producto de estas investigaciones. Segundo, cuestionarse sobre los supuestos que han permitido llevar a cabo estas investigaciones y sobre los conceptos que están sosteniendo sus teorías éticas.

\section{Los datos experimentales}

A pesar de que las numerosas investigaciones efectuadas en diferentes laboratorios tienen propósitos muy disímiles, sus resultados, sin embargo, han ido convergiendo y se pueden agrupar en cuatro tipos, cada uno con su alcance particular. 
1. Estimulado por lecturas de la literatura especializada, Haidt confirmó lo que se venía insinuando indirectamente. Cuando se les presenta un dilema moral a los sujetos - relaciones sexuales entre hermanos aunque se tomen las precauciones para evitar el embarazo-, éstos reaccionan emitiendo respuestas intuitivas, inmediatas, basadas en las emociones, y sólo posteriormente o no pueden justificarlas o lo hacen por medio de razonamientos que no corresponden al verdadero motivo de sus preferencias. En otras palabras, formulamos intuitivamente juicios para los que después buscamos argumentos. Esta disonancia cognitiva entre los juicios y sus avales argumentativos, entre juicios y razonamientos morales, es un dato que se repite(14-16).

2. El equipo de Greene ha trabajado las decisiones morales acudiendo al registro cerebral simultáneo. Cuando un individuo necesita escoger y decidirse frente a dilemas morales personales, se activan eléctricamente las zonas cerebrales asociadas a la emoción y cognición moral, activación que no es tan acentuada ante dilemas impersonales $(16,17)$. Estos descubrimientos concuerdan con los estudios de Damasio, para quien los juicios morales están mediados por las emociones(18). Mora encuentra que, cuando se formula un juicio moral, los sentimientos son centrales y estos afectos representan el primer impulso para continuar, son emociones básicas que finalmente se convierten en razonamientos morales a través del control de la corteza prefrontal(19).

3. Haggar y Eimer replicaron los experimentos de Liber, que habían dado un resultado inesperado porque postulaban que la voluntad libre para ejecutar actos es ilusoria $(20,21)$. Midiendo potenciales cerebrales, éste observó que procesos neuronales extraconscientes previos generan efectivamente los actos aparentemente volitivos, y que estas acciones sólo restrospectivamente son inexactamente catalogadas como producto de decisiones voluntarias. Concordante con este autoengaño, resulta igualmente ilusorio tenerse por autor cuando se ejecutan tareas irreflexivas, como mover con la mano una palanca, del mismo modo que nuestras acciones cotidianas no responden a la supuesta voluntad, elección y decisión, porque las causas efectivas residen en descargas electroquímicas infrapersonales que preceden a estas deliberaciones(22).
4. El estudio experimental de dilemas morales ha proporcionado parte importante de la nueva visión, porque los resultados obtenidos son concordantes entre investigadores procedentes de distintos centros univesitarios que no tienen intereses comunes, una suerte de verificación no intencional. Colocados los sujetos frente a diferentes situaciones imaginarias en que se juega la vida o muerte de otros individuos, los entrevistados respondieron en parte relacionados con las imágenes que se formaban en distintas zonas del cerebro, especialmente las que procesan emociones, un circuito que se extiende desde el lóbulo frontal hasta el sistema límbico o en la circunvolución cingulada anterior(23). En principio, ante los dilemas personales o aquellos que los afectan directamente, los individuoas utilizan bastante tiempo en pensar si creen que es lícito perjudicar directamente a una persona aunque sea para salvar a otra, pero, si llegan a la conclusión de que no se debe hacer, contrariamente la respuesta es rápida, casi sin vacilación. Parece probable que entender que es lícito personalmente dañar a alguien es pensar contracorriente y por ello se necesita tiempo para adquirir la convicción de que el juicio es correcto, lo que se acompaña de una mayor activación del cortex prefrontal dorsolateral, zona comprometida con la planificación y razonamiento $(24,25)$.

\section{"El cerebro moral"}

Este conjunto de investigaciones ha ido creciendo y complejizándose. Dejando de lado si apoyarse, aun de manera no intencional, en teorías procedentes de otras ramas científicas afines del conocimiento (biología evolucionaria, antropología biológica, psicología evolucionaria, sociobiología, ecología conductual, etc.) hace cuestionables o aun invalida algunas de sus hipótesis, las principales conclusiones se pueden resumir de la siguiente manera, aunque haciendo notar que los argumentos son más sofisticados y con más matices que los que se describen a continuación.

1) Los juicios morales nacen de la actividad del cerebro, son producto directo e indirecto de procesos electroquímicos de las neuronas distribuidas en red que están ubicadas en las distintas zonas corticales y subcorticales. Es una "constatación científica - la observación de que el cerebro reacciona ante las cosas según su configuración - para 
contextualizar y discutir los instintos viscerales que aportan los mayores beneficios..."(14). Dicho de otra manera, el cerebro es un mecanismo de toma de decisiones.

2) Los juicios morales están mediados por las emociones, afectos y sentimientos en alto grado. Estos juicios se denominan, de manera indistinta, intuiciones, instintos, sentido, competencias. Este es el segundo punto de partida de la neuroética que, por una parte, es poco preciso, vago y equívoco, y, por otra, significa contrapesar la racionalidad que ocupaba un lugar excesivo en las teorías morales tradicionales desde Aristóteles.

3) Estas intuiciones o juicios emocionales pueden entrar en conflicto al interior de cada sujeto o entre los individuos.

4) Cuando estos instintos entran en conflicto, las personas rara vez pueden ofrecer las razones o motivos que sustentan estos juicios, y si las dan se trata de argumentos elaborados con posterioridad. Esta es una comprobación de que las mejores o peores razones morales no dependen de su calidad como razonamientos, sino del modo como está construido el cerebro.

5) Las personas emplean más tiempo en apreciar situaciones morales personales, como dañar a un cercano, que impersonales, como perjudicar a un desconocido que se encuentra en otra ciudad. Pensar contracorriente, como el lesionar a alguien por mano propia, necesita ser meditado y sopesado con mayor detenimiento, con más parsimonia para tener más confianza, de ahí que sean las zonas prefrontales de la planificación y razonamiento las que se activan mayormente.

6) Los códigos emocionales son los más profundos en nuestro cerebro y aquellos que se reactivan cuando hay cercanía física y empatía hacia las personas. Nos afecta emocionalmente la situación de la gente necesitada y cercana, condición que no sucede con las gentes igualmente necesitadas pero que no conocemos, son distantes o no pertenecen a nuestro círculo.

7) Las zonas asociadas con la emoción y cognición moral resultan beneficiosas para ayudar a la gente de modo inmediato, porque tienen una función adaptativa central y bien definida, la de aplicarlas para sobrevivir y prosperar. Lo cual quiere decir que, sobre una primera impronta emocional, hemos generado y desarrollado códigos y mecanismos para sustentar los sentimientos y juicios morales rápidos y con ellos una respuesta social inmediata.

8) Estos son códigos más que milenarios, procedentes de la vida prehistórica y destinados a favorecer sólo a los cercanos y semejantes y repeler a los diferentes y extraños, códigos de funcionamiento más primitivos de nuestro cerebro, que fueron adquiridos a lo largo de la evolución de la especie desde el pleistoceno. Este cerebro paleolítico se desarrolló a partir de las relaciones sociales en que vivían los cazadores-recolectores. Eran pequeños grupos de no más de 130 individuos en los que el valor principal era el de la supervivencia. Por ello, al existir cercanía física se vuelven a activar estos códigos emocionales, y si no se da esta intimidad descargan eléctricamente otros códigos cognitivos más fríos, más calculadores, más alejados del sentido inmediato y urgente de supervivencia.

9) El altruismo innegablemente presente en el hombre no representa una refutación a la teoría de la función adaptativa de sobrevivencia. Altruismo significa invertir recursos propios para favorecer la adaptación del otro. Pues bien, desde los trabajos de Hamilton, éste postuló que el individuo altruista no trata de proteger al grupo sino a sus genes $(26,27)$. La eficacia biológica debe medirse en términos de la presencia de un alelo en el pozo de los genes que reúne a todos los de una población, dispersos por las células de los individuos que la componen y no por los individuos concretos, específicos que conforman la población.

10) Los trabajos de Wilson y Sober ofrecen, por el contrario, un mecanismo alternativo, quizás complementario, a la selección en el individuo, al reintroducir una selección de grupo que beneficia la cooperación al interior del grupo social en un nivel de organización más elevado, con una ética muy equitativa(28).

11) Se ha postulado la existencia de una moral común a toda la humanidad, basada en la estructura del cerebro. Aunque no existen pruebas concretas, se ha acudido a la hipótesis de Chomsky de una 
gramática generativa. Así como él habló de que nacemos con una gramática universal que nos permitiría poseer un lenguaje, así también poseeríamos una gramática moral común, que pone a nuestra disposición instrumentos para construir morales concretas, una suerte de caja de herramientas compartida que daría origen a las diversas morales culturales.

12) No hay ninguna regla, norma o código moral concreto que se desprenda de los experimentos neuroéticos, sino sólo vagas, ilusorias o ingenuas promesas destinadas a un futuro incierto y aún utópico ("una filosofía de vida basada en el cerebro")(14). El problema es que si se desprendiera alguna acción sería del tipo de juicio prudencial y no de juicio moral, como "si quieres sobrevivir en la situación X, entonces tienes que hacer Y" (12).

13) Como no existe una Regla de Oro que se pudiera homologar a la de Kant, se podría figurativamente enunciar un "imperativo adaptativo" evolutivo como: "actúa de tal manera que asegures tu supervivencia no dańando a los cercanos, porque tu destino está enlazado a la suya, y repele a los diferentes". También: "actúa con los demás de acuerdo con la medida en que compartan tus genes" (12,29).

14) El juicio moral, el libre albedrío, la voluntad, la autonomía y la responsabilidad son el resultado de interacciones electroquímicas en el cerebro y deben entenderse a partir de programas biológicos para la toma de decisiones, seleccionados por la evolución para la supervivencia del ser humano.

\section{La entificación de la realidad}

Las razones objetivas enunciadas por la neuroética fundamental sobre la génesis y función de la ética humana representan la ambición de fundar científicamente la moral, en abierta oposición a los intentos filosóficos y religiosos ancestrales. La riqueza de sus teorías, la aplicación consecuente de sus métodos y lo estimulante de sus conclusiones no impiden advertir las profundas dudas, incertidumbres y dificultades que generan. En lugar de entrar en los detalles ambigüos, en los informes contradictorios o en los contenidos dudosos de ciertas conclusiones, resulta interesante preguntarse por los supuestos, por lo no expresado, por lo que hace posible y sostiene todo el conjunto de la teoría neuroética. Es seguir las indicaciones de Heidegger porque, como él estipula, toda ciencia "pone a la base de todas las investigaciones experimentales un concepto muy claro de la constitución o estructura o índole de ser del ente de que en ella se trata", en este caso, del hombre como ser moral (30).

Partamos del hecho de que la neuroética se califica de ciencia moderna y que, por tanto, está investida de la autoridad que detentan las ciencias naturales en Occidente. Hace un siglo Husserl ya las caracterizó con precisión y nuestra ciencia se ajusta con exactitud a estas palabras: "El mérito del poder del naturalismo en nuestro tiempo consiste justamente en la energía con que trata de realizar, tanto en la teoría como en la práctica, el principio del rigor científico en toda la esfera de la naturaleza y del espíritu; en la energía con que aspira a resolver, científicamente a su juicio, los problemas filosóficos del ser y del valor con la voluntad propia de las ciencias naturales"(31).

Zubiri ha advertido que el pensamiento occidental, incluido el actual pensamiento por antonomasia que es el de la ciencia positiva, se ha caracterizado por una progresiva "entificación de la realidad", en cuya base se descubre una creciente "logificación de la inteligencia"(32). ¿Qué significa entificación de la realidad?

Al presentarle a un individuo un dilema moral y simultáneamente medir las zonas cerebrales involucradas, el investigador efectúa dos acciones. Por un lado, deja de comportarse con el sujeto de manera habitual y lo coloca delante (vor-liegen) para captar su aspecto (Aussehen) o sus reacciones ante los estímulos. Por otro, no atiende a la situación global en que se encuentra la persona y se concentra sólo en el funcionamiento de su cerebro, según se va registrando en los aparatos de medición. Esta separación o prescindencia de la situación o mundo cotidiano se puede llamar des-mundanizarlo (Ent-weltlichung), que simultáneamente es nivelación y abstracción de la vida natural, y que compromete al investigador pero especialmente al interrogado(33).

Esta es una conducta activa del investigador, para ver (Sicht) un comportamiento adoptado pre- 
viamente, que provoca dos modificaciones en el ver habitual, para ejecutarlo de una cierta manera precisa, tanto en el sujeto de experimentación como en el del científico. Por una parte, este ver del entrevistado ya no es más el ver del ver-en-torno (Umsicht), que adoptan las personas cuando se deciden a efectuar un movimiento, por ejemplo, en el juego de ajedrez, que prestan atención y consideran todos los ingredientes involucrados (cómo disponer las piezas, cómo sentarse, cómo tomar su pañuelo para secarse la traspiración, cómo no errar al desplazar el alfil), ni tampoco este ver se preocupa más por el estado emocional del contrincante, ya no es más un ver-por-el-otro (Rücksicht). Por otra parte, el ver del investigador sigue siendo un ver pero que se define por fijarla-vista o dirigir-la-vista (Hinsicht) a una particularidad de lo que pone por delante (vor-kommen), abstrayéndose del entorno o sacándolo de todas las circunstancias que rodean al sujeto.

Este cambio del modo de mirar, desde el ver-entorno o del ver-por-el-otro (de ambos) al fijar-lavista (del entrevistador), trae aparejado un vuelco mayor, una mutación en el modo de ser del sujeto estudiado. El investigador ya no se "preocupa" (fürsorgen) más por la condición de su amigo-quejuega-ajedrez sino se "ocupa" (besorgen) de él en cuanto es un objeto-ante-los-ojos (Vorhanden), y así es posible medirle las variaciones y modificaciones de su cerebro. Este cambio es un cambio en la comprensión de ser, desde ser su amigo a ser-ante-los-ojos. Es esta transformación la que posibilita que el universo de lo ante-los-ojos sea el tema único de la investigación: cerebro, neuronas, sinapsis, tiempo de respuesta, neurotrasmisores, descargas electroquímicas(34).

Esta conversión ejecutada por la ciencia es la entificación de la realidad, es aprehender la realidad como presencia (Anwesen), pero ésta significa simultáneamente entificación del ser humano, plena presencia de lo presente, con la forma de ser propia del ser-ante-los-ojos que vive, se mueve y adapta a un ambiente circundante. La ciencia de la neuroética es la culminación de este doble proceso que viene gestándose desde Platón hasta la actualidad y que ha dado resultados más espectaculares mientras más se ha atenido a estos supuestos ontológicos. En otros términos, fundar la moral a partir de la ciencia significa dar por aceptados estos presupuestos metafísicos que están operando en forma oculta en cada una de las afirmaciones de la neuroética.

Heidegger pretende dar un giro y superar la entificación del ser humano por una nueva manera de abrir la realidad. No se trata de que él invalide, desautorice o arrumbe este proceder, sino que quiere enriquecerlo con otra perspectiva, adoptar una manera inédita de des-cubrir lo real porque, como afirma su discípulo Gadamer, la ciencia no es "la última instancia ni la única portadora de la verdad"(35).

El hombre no es un ente algo más complejo que los demás, un "animal racional" (animal rationale), según la definición de Aristóteles, que se diferencia en sólo el 3\% de su constitución genética del resto de las especies más cercanas, o la divergencia global de secuencia es modesta cuando se refiere específicamente a la organización del cerebro, el 1 por 100, pero que, como zóon lógon ékhôn, sigue siendo un ser-ante-los-ojos que se tiene que adaptar a su medio. Se trata de que su modo de ser es radicalmente distinto, porque es el único ser que comprende el ser (Seinsverständnis) y por ello es Dasein, antes de efectuar cualquiera investigación.

¿Qué quiere decir? Dasein es una palabra alemana corriente que se usa para designar la existencia pero que significa literalmente ser-ahí. Porque es el hombre quien, en cada uno de sus actos, trata de ser de un modo o de otro, cada acción la ejecuta con vistas al ser que va a ser. Este "en vista de" es precisamente la comprensión del ser del hombre mismo. Con palabras más directas, en cada acto estamos abiertos a las cosas, a los otros y a uno mismo, comprendiéndolos de mejor modo o de peor forma; aquello con lo que tenemos que habérnosla "es" de tal o cual manera, o sea, cuando decimos que algo "es" de esa manera queremos decir que comprendemos desde el "ser", o el "ser" es el acceso a toda nuestra realidad. En una frase, somos Dasein porque, a diferencia de todas y cada una de las demás criaturas, nos es presente $(D a)$ el ser (Sein) mismo, vivimos desde el ser.

Esta constitución fundamental trae variadas consecuencias. Antes mostramos que el procedimiento científico consiste en des-mundanizar tanto 
al individuo estudiado como al investigador. Lo que sucede es que tanto el uno como el otro son ser-en-el-mundo (In-der-Welt-sein), vale decir, no es que ellos "tienen" un mundo que puede o no tomarse en cuenta, sino que cada uno "es" en el mundo; en términos justos, al des-mundanizarlo se está desnaturalizando su radical modo de ser, porque la mundanidad (Weltlichkeit) es parte constitutiva de su ser mismo. El ser-ante-los-ojos tiene un medio ambiente que lo rodea, el Dasein es su mundo y se entiende y se da aconocer a partir de él; el ser-ante-los-ojos responde al medio, el Dasein abre el mundo y al abrirlo se abre él mismo; el ser-ante-los-ojos posee rasgos, el Dasein es en-cada-caso-mío (Jemeinigkeit); el ser-ante-losojos ejecuta actos según su constitución, el Dasein es proyecto de existencia que lleva a cabo desde su futuro o ad-viniendo a sí (zu-kommen); el serante-los-ojos tiene atributos y despliega sus disposiciones heredadas, el Dasein es sus posibilidades; el ser-ante-los-ojos nació y es producto de su desarrollo y evolución, el Dasein es temporalidad finita; el ser-ante-los-ojos tiene una naturaleza, el Dasein es histórico.

Ser-en-el-mundo es igual a decir que el hombre en cuanto Dasein es esencial apertura (Erschliessung), desde siempre lanzado en medio de las cosas y manejando los útiles, absorvido por el barullo de la cotidianidad, teniendo que arreglárselas mejor o peor con los otros, nunca habiéndose dado el fundamento a sí-mismo ni tampoco la razón última de su ser, ni menos sabiendo a ciencia cierta cuándo esta terminará, aunque está cierto de que en cualquier momento es suficientemente viejo como para morir. Ser-en-el-mundo es por tanto "existencialidad" (proyecto), "facticidad" (arrojado en) y "caída" (Verfallensein) (aspirado por sus quehaceres), según Heidegger(36-38). Es lo inverso de un ser encerrado en sí, una especie de cerebro emplazado dentro del cráneo que responde a los estímulos provenientes del medio seleccionándolos, y que se comporta en acuerdo con su disposición genética y epigenética, que genera respuestas propias o es un sistema neuronal interconectado proyectivo.

\section{La existencia ética}

La neuroética parte de un concepto de la moral sin preguntarse qué es lo moral propiamente tal; el concepto de moral que utiliza es el "cotidiano"; da por supuesta la realidad de esta moral vigente en la vida corriente como otro dato más de su estudio y de allí comienza a investigar cómo se manifiesta objetivamente y cómo se generó históricamente desde el hombre prehistórico. Por decirlo así, es a partir de esta presencia actuante hoy - la moral de término medio (durchschnittlich) — donde busca las expresiones actuales y las huellas o trazas en el pasado. Pero cabe lo inverso, preguntarse qué es lo moral, cómo es posible que se dé en el hombre algo así como la ética, qué es lo que hace que exista lo moral más allá de cómo nació concretamente. Frente a la moral como serante-los-ojos está la moral como posibilidad, se entiende, posibilidad de ser de cierta manera en el mundo.

Partamos por la ética de la vida inmediata y regular. Para el hombre promedio (das Man), la conciencia moral se aparece producto de un autodesdoblamiento interior objetivante que adquiere la figura de un tribunal, de una audiencia o de una autoridad. Hay una suerte de examen a sí mismo, una autocontemplación en la actitud de un espectador, que evalúa críticamente su conducta con un ideal, con una excelencia que posee un derecho propio en cuanto medida. La conciencia tantea, compara, examina, saca cuentas, tasa, regula y emite un veredicto. En palabras de Heidegger, "la interpretación cotidiana se mantiene en la dimensión del calcular y compensar, (...) según el 'debe' y el 'haber'" (33). Hay un doble componente. Por una parte, una conducta de cómputos y expectativas, como de alguien que maneja un negocio y que, en cuanto negocio, está a entera disposición del propio sujeto, lo administra como pertenencia privada, lo tiene a su mano sin restricción alguna. Por otra, tiene el carácter de un fenómeno de conciencia, de una "vivencia" que se cerciora de no haber hecho nada malo y por tanto no tener motivos para experimentar remordimientos; o, por el contrario, de una "vivencia" que más bien es un olvido de la conciencia que elude su responsabilidad ante su accionar reprensible; o, por el contrario, hay "la tranquilidad de conciencia" que denota "ser bueno" ante sí. Todo este proceso de rendir cuentas es manifestación directa de un supuesto primario, del poder darcuenta-de-sí. Según Heidegger, es la tesis del idea- 
lismo moral que se remonta a Kant, que pone el origen de la falta en el acto de la libertad, y por ello también en la libertad está la capacidad de reparación, o sea, en una omnímoda disposición de sí por sí mismo(39).

Pero puede ser que en la plena soberanía y autodisposición no resida lo propio del ser humano. Ya vimos que el existente es apertura al mundo y que en este abrir el mundo se comprende a sí-mismo. La conciencia moral (Gewissen) da a comprender algo de alguna manera, da a conocer alguna situación o estado, de modo más o menos claro, directa o indirectamente. Significa que la conciencia moral pertenece a la estructura de apertura de la existencia. El llamado $(R u f)$ de la conciencia es una voz que da a entender, aunque esta voz no sea audible, una voz insonora que sin embargo se escucha internamente. ¿A quién le dice? Le habla a la propia existencia y le dice algo que le concierne a ella misma. ¿Qué dice? Nada de lo que quepa hablar y hablar, someter a discusión o regateo, nada del parloteo usual, nada de lo que aparezca como presente en el mundo, nada de lo que se muestra ante los ojos como objeto. ¿¿Sobre qué habla? Invoca a "volverse hacia sí mismo, es decir, hacia su más propio poder-ser", a recuperarse en la elección de sí. ¿A recuperarse de qué? De su extravío en el tráfago de la vida ordinaria, de las habladurías, del afán de novedades, de la charla de la gente o del "uno". Pero este sí-mismo no es un sí que se autodetermina a voluntad (Selbstbestimmung), sino se autoelige (Selbstwahl); él nunca tiene el poder de autodisponer de sí por completo y determinarse, porque él nunca ha sido su propio fundamento, nunca se ha dado su propio ser. La conciencia moral no juzga, ni condena, sino que da a entender nuestra condición básica: que no somos fundamento de nuestro ser, que somos seres intrínsecamente finitos, que esta negatividad es nuestra raíz, que somos ser-para-la muerte como nuestra más propia y auténtica posibilidad de ser y que, enfrentados a esta condición ominosa y siniestramente inquietante (unheimlich), la eludimos inmediata y regularmente (zunächst, zumeist), entendiéndonos como ser-ante-los-ojos con plena soberanía y autarquía(40-43).

\section{Estímulos}

1) La neuroética es un intento serio de las cien- cias positivas por explicar el fenómeno de la moralidad, tanto en su vertiente de bioética aplicada como de fundamentación de la ética, a partir de datos positivos, situaciones experimentales y certeza verificable.

2) La neuroética fundamental postula que la moral es el resultado final de interacciones electroquímicas de las redes neuronales y de programas biológicos al interior de las diversas zonas interconectadas del cerebro, destinados a la toma de decisiones para la supervivencia del ser humano y seleccionados por la evolución desde la prehistoria.

3) Esta concepción resulta un avance, un estímulo y un giro en los estudios ejecutados hasta hoy en el campo de la bioética, una especie de caja de herramientas que puede ser utilizada por diferentes teorías alternativas de manera productiva y creadora. Es un aire renovador que revitaliza las publicaciones algo estancadas por la repetición de viejas teorías, por el intento de asombrar con nuevas concepciones - producto de las modas académicas - o por apoyarse en conclusiones apresuradas.

4) Las ciencias naturales a las que acude la neuroética son el producto de ciertos supuestos básicos, dentro de los cuales el principal consiste en transformar al ser humano en un ser-ante-los-ojos y con ello convertirlo en sujeto de experimentación. De ahí surgen las denominaciones con que se pretende caracterizarlo científicamente, denominaciones que no han reflexionado suficientemente sobre sus implicancias ontológicas: cerebro que piensa, mente computacional, hombre neuronal, cerebro empático, cerebro ético, self sináptico.

5) La entificación del sujeto humano es un proceder que objetiviza igualmente a la ética y así ésta aparece como un dato positivo real, puesto delante, que puede ser calculado, medido, registrado, tasado, contado.

6) Las interrogantes de Heidegger van por otros caminos. En lugar de apostar por la certeza y verificabilidad de los hechos que aduce la neuroética para justificar sus teorías éticas, se pregunta por lo que hace posible que estos hechos se conviertan 
en tales, por su condición de posibilidad.

7) Más allá de considerar las distintas etapas de la historia de Occidente que consistieron en entificar la realidad, interesa que esta entificación impidió mostrar o que se diera a conocer lo esencial e inherente del hombre, que es un ser-en-el-mundo. La diferencia con todas las demás criaturas no radica en la mayor o menor cantidad de atributos que compartimos o no compartimos con ellas, sino en que nuestro modo de ser es único y definitorio: somos comprensores de ser y, con ello, nos comprendemos, esto es, el ser es nuestra manera de acceder a la realidad.

8) La ética deja de entenderse a partir de su génesis, de si y cómo nació concretamente en el pleistoceno. Aparece como una posibilidad de existen- cia que nos da a conocer algo de nosotros, algo que no puede ser experimentado de manera objetiva, porque la objetividad es un impedimento para que se exprese su llamado. La voz silenciosa de la conciencia moral nos convoca a que enfrentemos con decisión a que no somos autónomos, que no somos seres autárquicos que disponemos a voluntad de nuestra libertad, que no somos dueńos de nuestro ser. Más bien nos hace saber que nunca hemos dispuesto de nuestro fundamento, que somos negatividad intrínseca referida a la muerte como la más propia y auténtica posibilidad de ser.

9) Las diferencias entre ambas perspectivas invitan a una reconsideración de los alcances de la ciencia positiva: no es la última verdad ni el único camino para alcanzarla.

\section{Referencias}

1. Crick F. The atonishing hypothesis: The scientific search for the soul. New York: Simon \& Schuster; 1994.

2. DANA Foundation. Neuroethics: Mapping the field. New York: The Dana Press; 2002.

3. Dick PK. Do androids dream of electric sheep? New York: The Random House; 1968.

4. Searle JR. The mystery of consciousness. New York: New York Review of Books; 1997.

5. Changeux J-P, Ricoeur P. Ce qui nous fait penser: La nature et la règle. Paris: Odile Jacob; 1998.

6. Changeux J-P. Du vrai, du beau, du bien: Une nouvelle approche neuronale. Paris: Odile Jacob; 2008.

7. LeDoux J. The synaptic self: how our brains become who we are. New York: Viking; 2002.

8. Dennett D. Sweet dreams: Philosophical obstacles to a science of consciousness. Cambridge, Mass: The MIT Press; 2005.

9. De Vignemont F, Singer T. The empathic brain: how, when, and why? Trends in Cognitive Science 2006; 10: $435-441$.

10. Evers K. Neuroéthique. Quand la matière s'éveille. Paris: Odile Jacob; 2009.

11. Roskies A. Neuroethics for the new millennium. Neuron 2002; 35: 21-23.

12. Cortina A. Neuroética y neuropolitica. Sugerencias para la educación moral. Madrid: Tecnos; 2011.

13. Haidt J. The emotional dog and its rational tail: A social intuitionist approach to moral judgement. Psychological Review 2001; 108: 814-834.

14. Gazzaniga MS. The ethical brain: The science of our moral dilemmas. New York: The Dana Press; 2005.

15. Gazzaniga MS. Who's in charge? Free will and the science of the brain. New York: Herper Collins; 2011.

16. Greene JD. From neural "is" to moral "ought". What are the moral implications of neuroscientific psychology? Natural Review of Neuroscience 2003; 4: 847-850.

17. Greene JD, Sommerville RB, Nystrom LE, Darley JM, Cohen JC. An fMRI investigation of emotional engagement in moral judgment. Science 2001; 293: 2105-2108.

18. Damasio A. Descarte's error: Emotion, reason, and the human brain. New York: G.P. Putnam's Sons; 1994.

19. Mora F. Neurocultura. Madrid: Alianza; 2007.

20. Haggard P, Eimer M. On the relation between brain potentials and the awareness of voluntary movements. Experimental Brain Research 1999; 126: 128-133.

21. Liber B. Unconscious cerebral initiative and the role of conscious will in voluntary action. Behavioral Brain Sciences 1985; 8: 529-566.

22. Brasil-Nieto JP, Pascual-Leone A, Valla-Sole J. Focal transcranial magnetic stimulation and response bias in a forcedchoice task. Journal of Neurology, Neurosurgery and Psychiatry 1992; 55: 954-966.

23. Greene JD, Nystrom LE, Engell AD, Darley JM, Cohen JD. The neural basis of cognitive conflict and control in moral judgment. Neuron 2004; 44: 389-400. 
Las ambiciones de la neuroética: Fundar científicamente la moral - Gustavo Figueroa

24. Foot P. The problem of abortion and the doctrine of the double effect. Oxford Review 1967; 5: 5-15.

25. Hauser MD. Moral Minds: How Nature Designed Our Universal Sense of Right and Wrong. New York: Harper; 2006.

26. Hamilton WD. The evolution of altruistic behavior. American Nature 1964; 97: 354-356.

27. Hamilton WD. The genetical evolution of social behavior. Journal of Theoretical Biology 1964; 7: 1-52.

28. Wilson DS, Sober F. Reintroducing group selection to the human behavioral sciences. Behavioral Brain Sciences 1994; 17; 585-654.

29. Kant I. Kritik der reinen Vernunft. Erster Teil. Werke. Band 3. Darmstadt: Wissenschaftliche Buchgesellschaft; 1968.

30. Heidegger M. Einleitung in die Philosophie. Gesamtausgabe Band 27. Frankfurt: Klostermann; 1996.

31. Husserl E. Die Philosophie als strenge Wissenschaft. Frankfurt: Klostermann; 1981.

32. Zubiri X. Los problemas fundamentales de la metafísica occidental. Madrid: Alianza; 1994.

33. Heidegger M. Sein und Zeit. 10. Aufl. Tübingen: Niemeyer; 1963.

34. Heidegger M. Prolegomena zur Geschichte des Zeitsbegriffs (Sommersemester 1925). Gesamtausgabe 63. Frankfurt: Klostermann; 1979.

35. Gadamer H-G. Was ist Wahrheit? Gesammelte Werke 2. Hermeneutik II: Wahrheit und Methode: Ergänzungen, Register. 2.Aufl. Tübingen: Mohr Siebeck; 1993: 43-87.

36. Heidegger M. Brief Über den "Humanismus". En: Heidegger M. Wegmarken. Gesamtausgabe 9. Frankfurt: Klostermann; 1976: 313-364.

37. Heidegger M. Ontologie. (Hermeneutik der Faktizität). Gesamtausgabe 63. Frankfurt: Klostermann; 1982.

38. Figueroa G. Bioethics today: Heidegger's questions. Revista Médica de Chile 2011; 139:1377-1382.

39. Cerezo P. De la existencia ética a la ética originaria. En: Cerezo P, Duque F, Leyte A, Martínez F, Peñalver P, Rodríguez R, eds. Heidegger: la voz de tiempos sombrios. Barcelona: Ediciones del Serbal; 1991: 11-79.

40. Figueroa G. Bioethics of Sigmund Freud's death: Euthanasia or appropriation? Revista Médica de Chile 2011; 139: 511-516.

41. Heidegger M. Kant und das Problem der Metaphysik. 2. Aufl. Gesamtausgabe 3. Frankfurt: Klostermann; 2010.

42. Heidegger M. Die Grundbegriffe der Metaphysik. Welt, Endlichkeit, Einsamkeit (Wintersemester 1929-1930). Gesamtausgabe 29/30. Frankfurt: Klostermann; 1983.

43. Heidegger M. Zollikoner Seminare. Protokolle - Zwiegespräche - Briefe. 2. Auflage. Frankurt: Vittorio Klostermann; 1994.

Recibido: 13 de marzo de 2012

Aceptado: 22 de abril de 2012 